\title{
Intelligence or Counter Intelligence? Cognitive and Behavioral Implications of Mediated Cyborg Images on Children
}

\author{
Indira Srinivasan $\mathbf{M}^{*}$
}

St. Josephs Degree and PG College, Hyderabad, Telangana, India

\begin{abstract}
"Human mind contained the 'indelible stamp of his lowly origin' Human could differ from animals only by their ability to control these passions to suppress the beast within"- Charles Darwin, The Decent of man, 1871.

Neurological system plays a significant role in establishing the human as intelligent beings on the earth, distinguishing it from its predecessor. With its well built communication network and mechanism and, nervous system prepare the body and mind to react to any occasion through reciprocate actions. There is a well-built communication network system internally that facilitates communication among the innumerable cells so that the internal body organs function properly. What if when artificial intelligence in the name of cyberog is here to think, deliberate and act on our behalf and where are we heading to?

How is it going to affect our abilities like thinking, reasoning, and being analytical? What happens to the socially constructed systems and agencies like families, schools, organizations and institutions that groom and shape individuals from birth to death? What might happen to the cultural diversity of this universe rooted deeply in language, gender, race, ethnicity, place of origin, physical and biological features and capabilities at large are vague, wild questions posed in dark.

Cyber technologies are to stay with us. Their omnipotent and ubiquitous presence reached a stage that the humanity started cohabitating with them. They are part of daily life, as human are employing them at every level. Children as young as two or three are absorbed in operating smart phones, spell bounded by the colorful moving images, sounds, music and mobile games. Computer-mediated education has long ago replaced the face to face interaction, limiting the teacher to a facilitating role, as if human are lacking physically, emotionally and intellectually (Voithofer, R.J.,). Meticulous updating of technology is constantly forcing the man to adapt to it, involving huge politics of economy. Socially, you are not fit without having adapted to the latest technology.

The present study would like to deconstruct the politics of economy and polity, while unearthing the sociocultural, physiological and psychological impact of Cyborg technologies among children using the secondary data. By reviewing the existing literature in this aspect the study would like to assess the cognitive and behavioral implications of mediated cyborg on children.
\end{abstract}

Keywords: Cyborg; Neurological system; Artificial intelligence; Cognitive and behavioral changes; Posthuman theoretical framework; Asian American Youth

\section{Introduction}

Since antiquity, inventions and innovations are part and parcel of human civilization and the humanity have learnt to cope with each innovation starting from the 'fire', and proceeded with the 'Wheel' and had learnt to adopt them in the daily life. When the 'Industrial Revolution' taught it to produce and distribute mechanically to mass markets for consumption, away from its place of origin, humanity could witness a section of elite, economically strong, ruling class colonizing vast sections of people of this planet. With the passage of time, human civilization has reached a phase where innovations in the form of communication and information technologies have created borderless societies, invading the time and space, connected to computers. What is at stake for the humanity when the technologically augmented artificial human creations have started replacing the biologically and physiologically built and evaluated human body over billions of years with its own set of unique intelligence to act and react to the facts, incidents and situations? What might happen to peculiarly human abilities of emotions, feelings, compassion and tolerance? What might happen to our physical, psychological, socio-cultural abilities and diversity?

Ever since the time when Manfred E. Clynes and Nathan S. Kline coined the term 'Cyborg' in an article 'Cyborg and Space' during 1960s, technologically augmented human and machine form of 'Hybrid' bodies with a combination of biological and artificial body and mind have started appearing widely in science fictions, literature, films electronic, mobile and new media.

Though the revolution in the field of information and communication technology is initially put to military and defense use and intelligence, of late they have started invading every sphere of human activity. Its pervasive presence was felt in entertainment, medical, genetic, space, and marine research denoting its multiple applications in these fields. Yet, this is not a cause for getting panic. When the research evidence started demonstrating that the artificial intelligence has started becoming part of civilian life, away from

*Corresponding author: Indira Srinivasan M, Associate Professor, St. Josephs Degree and PG College, Hyderabad, Telangana, India, Tel: 9490190815; E-mail: mannar.indira@gmail.com

Received August 22, 2017; Accepted September 22, 2017; Published September 25, 2017

Citation: Indira Srinivasan M (2017) Intelligence or Counter Intelligence? Cognitive and Behavioral Implications of Mediated Cyborg Images on Children. J Mass Communicat Journalism 7: 349. doi: 10.4172/2165-7912.1000349

Copyright: (c) 2017 Indira Srinivasan M. This is an open-access article distributed under the terms of the Creative Commons Attribution License, which permits unrestricted use, distribution, and reproduction in any medium, provided the original author and source are credited. 
medical and military uses, it is a cause for serious concern that ought to be explored and addressed effectively.

Human beings, referred as 'Avatars' are present online interacting on the virtual space using texts, voice, sounds and images for hours. Social networking sites are bustling with hectic activities. Birthdays, weddings and anniversaries, visits, tours, organizational anniversaries, and a plethora of personal and official activities including promotions, job changes are notified, posted, shared and exchanged within no time online, via social network sites. Since we are living in the information age, obsessed with the mediated technologies namely Wi-Fi connected smart phones, computers, and other smart, mobile electronic gadgets, the consequences it may have on humanity in general and youth in particular is a cause for serious concern.

\section{Cognitive and Behavioral Implications for Children: A Quick Review of Literature}

Electronic and mobile media has a profound impact on children. According to Cris Rowan, a Pediatric Occupational Therapist, the time is ripe for a 'Balanced Technology Management'. She announces that parents, teachers, health professionals, government, researchers and technology production corporations must join hands in maintaining a healthy distance in using technology in our daily life.

Excessive technology usage among children is snatching their precious childhood away from them and 'detaching' them from the humanity. This is leading cause for rise in psychological and behavioral disorders, compelling children to undergo psychotherapy [1]. There is a considerable rise in the usage of entertainment technology in the past decade and children as young as one year old are affected by it, depriving their sensory, motor and attachment development. This is resulting in hazardous health disorders like delay in growth, obesity, lack of attention, illiteracy and mental illness. Several developed countries of the world have declared 'Media Violence' as 'Public Health Risk', as it is leading to aggressive child behavior, affecting the development of 'Cortex' and impulse control.

$80 \%$ of the studies reported negative health impact of media on children leading to obesity, smoking, sexual behavior, drug use, alcohol use, low academic achievement and ADHD [2], prompting countries like France banning TV shows for the children below three years. Constant exposure to media in some form or other is leading to media addiction. $12 \%$ of boys and $8 \%$ of girls addicted to video games show pathological patterns of addiction leading to.

Attention deficit hyperactivity disorder ADHD [3] in USA. This is particularly high among children addicted to the Internet. Addicted children are depressed if forced to stay away from the technologies $[4,5]$. Reported heavy activation of sympathetic nervous system among internet addicts due to stronger blood volume pulse and respiratory responses, and the weaker peripheral temperature reactions.

Addiction to the media and the Internet is a global phenomenon today as $8.5 \%$ of video game players in the USA are clinically addicted [6]. 12\% of children in Britain, 2.4\% in Korea in the ages 9-39 years are addicted and another $10.2 \%$ are likely to join the list. Addicted children are obsessed with playing electronic games to the extent of depriving sleep, disruption of daily life and losing grip on reality. When they are disrupted from playing, addicted players are depressed and withdrawn.

Addiction to the Internet and excessive online activity is equally threatening as the socio-psychological health of the children. They suffer from loneliness, low self esteem, poor socializing skills, high dissociation, and higher impulse deregulation [7].
When we look at the physical and psychological disorders that the children are encountering due to excessive time spent on video, online games and the internet, the list is mind boggling.

Several studies have proved that 2 hours increase in TV viewing is leading to physical and psychosocial health disorders among children and lowering sedentary reduces BMI. Excessive TV viewing and video game accounts for $60 \%$ of childhood obesity, a phenomenon referred currently as "North American epidemic" [8]. Obese children are at increasing risk of attracting cardiovascular diseases, and Type 2 diabetes.

Rapid technological advancements are developing sedentary societies with high frequency, duration and intensity of sensory stimuli. Children who are absorbed in this virtual world are disconnected to the real world, deprived of the physical activities and meaningful interaction.

Children who are exposed to more than 1-2 hours per day recommended hours of media are prone to develop a $60 \%$ increase in psychological disorders. Technology overuse may result in sensory over-reactivity [1], lower life satisfaction and elevated levels of anxiety and depression [9]. Delayed vestibular maturation correlates significantly with sensory integrative dysfunctions like slow vision processing, hearing impaired, and reading disabilities.

From mediated technologies, humanity is successful in creating Artificial Intelligence (AI) that can replace the naturally evolved human intelligence. Cyborg is one such creation, projected as an extended form of man with innumerable capabilities, taking any shape, form and sex (male or female), with an ability to accomplish tasks beyond the ability of biologically constructed body.

Oxford English dictionary defines 'Cyborg' as a "person whose physical tolerances or capabilities are extended beyond normal human limitations by a machine or other external agency that modifies the body's functions; an integrated man-machine system. The term emerged as a blend of cyb [ernetic] - pertaining to Norman Weiner's cybernetics, "the entire field of control and communications theory, whether in the machine or animal" - ad org [anism]. It is "an organized body, consisting of mutually connecting and dependent parts constituted to share a common life." The cyborg was a human, but its non-human extensions make it something else entirely. Like Marshall McLuhan's "extensions of man," the cyborg represents the relationship between organic bodies and media technologies that extend either "bodies through space" or the "central nervous system itself".

Cyborg draws a parallel between naturally evolved human physiology built upon nerves and cellular system and the computers made electronic circuits. Brain acts as a central processing unit, controlling the human body. A device is inserted in the human body to replace any missing organ and the brain interacts and synthesizes with this external agency to form a Cyborg.

The machine part is a medium for the communication of human consciousness and integrates with the organically evolved human body to produce a 'hybrid' form.

Cyborg has no parents [10]. Though it is put to several positive uses to improve the human capacity, allowing them to optimize their internal body system to suit environments, there are monstrous forms of cyborgs demonstrated on screen like the one in Mary Shelley's Frankenstein, drawing the difference between the good and bad uses of technology and its implications to the humanity. Cyborg is a social reality as well as a science fiction today creating an optical illusion. It is eroding the thin 
Citation: Indira Srinivasan M (2017) Intelligence or Counter Intelligence? Cognitive and Behavioral Implications of Mediated Cyborg Images on Children. J Mass Communicat Journalism 7: 349. doi: 10.4172/2165-7912.1000349

line of difference between the biologically evolved human civilizations with that of manmade mediated technology [11].

Donna Haraway's Cyborg Manifesto could critically deconstruct its possible socio, psychological, economic and political implications on humanity. Though modern medicine is making the best use of nanotechnologies and other implants, they are nothing but coded devices, originated away from the sexuality. Though Donna made several satirical observations of cyborg as a creature of post-gender world, she made an effort to document the political economy of their origin, ownership and control of these devices and the amount of digital divide it may further create on this planet [12].

Though we can assume a genderless, less hierarchical Cyborg society, it completely erodes the very concept of family, society and various agencies that the societies built overtime namely faiths, customs like religion and other human emotions [13]. It is a creation meant for political and military supremacy in this polarized world and hence it cannot be observed through the lenses of Center peripheral frame works of the early 21 st century. It is also beyond the post colonial theories based on ethnicity, race, gender and identity. The theorists, practitioners and the researchers of media, society and culture had long built their works based on Marshall McLuhan is now referring to utopians characterized as "inebriated with the potential of new technology. More recent discussions have been anchored in the work of theorists including Walter Benjamin, the Situationists, Jean Baudrillard, Gilles Deleuze, F ilix Guattari, Paul Virilio, Jacques Lacan, Luce Irigaray, and Donna Haraway [14].

Unlike the colonial domination with a 'civilization mission', which involved physical invasions and expansions for supremacy, electronic mission of connecting people in a border less society has economic, political and military agendas that erodes concepts, including systems, agencies, traditions, norms and culture, establishing a homogenous, mechanical, hybrid consumer culture and society [15].

\section{Conclusion}

We have already been witnessing the 'Data Sweat shops' where thousands have been employed on paperless, computer mediated environs for hours that squeezes the flesh, blood and labor of young men and women in the 'silicon valley' of the $21^{\text {st }}$ century. Cultural industries are prominently projecting the technological marvels as themes, widely applying post-human, Hybrid technologies in content, formation, distribution and consumption, we need post-human media theories to gauge its impact on the humanity in general and the youth in particular that are avid consumers of these mediate images, sound and text.

When we observe the Medical advancements like surrogacy, genetically modified iPS cells and various technological implants to enhance or to rectify the defects in the body and nervous system, we are not far away from the milestones and goals mentioned in the 'Avatar' Project-2045. These developments involve several legal and ethical implications as well and the entire issue should be studied in totality.

\section{Limitations}

The article provides the proof for the cognitive and behavioral implications for children as a result of constant exposure to mediated Cyborg technologies based on the available literature. It provides the background and theoretical framework, which can be tried and tested using qualitative and quantitative research techniques. The article has absolutely no conflict of interest and was written out of my own curiosity to work on this area, provided I shall get funding.

\section{Implications}

A full length study involving a cross section of the population on any given geographical location can provide insights on the way the children are affected due to the exposure to the mediated Cyborg in the wake of emerging challenges like 'Blue Whale' gaming that is taking a heavy toll of the young adolescents.

\section{References}

1. Rowan C (2010) Impact of Technology on young children's development.

2. Murray JP, Liotti M, Mayberg HS, Pu Y, Zamarripa F (2006) Children's brain activations while viewing televised violence revealed by fMRI. Media Psychology 8: 25-37.

3. Gentile D (2009) Pathological video game use among youth 8 to 18: a nationa study. Psychological Science 20: 594-602.

4. (2011) Tech addiction symptoms rife among students. CBC News.

5. Lu DW, Wang JW, Huang AC (2010) Differentiation of Internet Addiction Risk Level Based on Autonomic Nervous Responses: The Internet-Addiction Hypothesis of Autonomic Activity. Cyberpsychol Behav Soc Netw 13: 371-378.

6. Tracey M, Harris I (2007) Video Game Addiction: Is it Real?

7. Ghassemzadeh L, Shahraray M, Moradi A (2008) Prevalence of internet addiction and comparison of internet addicts and non-addicts in Iranian high schools. Cyber Psychology \& Behavior 11: 731-733.

8. Strauss RS, Pollack HA (2001) Epidemic increase in childhood overweight 1986-1998. Journal of American Medical Association 286: 2845-2848.

9. Mentzoni RA, Brunborg GS, Molde H, Myrseth H, Skouverøe KJ, et al. (2011) Problematic video game use: Estimated prevalence and associations with mental and physical health. Cyberpsychology, Behavior \& Social Networking 14: $591-596$

10. Haraway D (1991) A Cyborg Manifesto: Science, Technology, and SocialistFeminism in the Late Twentieth Century.

11. María F (1999) Postcolonial Media Theory. Art Journal 58: 58-73.

12. Angie (2010) Screen time linked to psychological problems in children. Bristol University.

13. Caldwell CD, Cunningham TJ (2010) Internet addiction and students: Implications for school counselors. American Counseling Association, VISTAS Online.

14. De Berardis D, D’Albenzio A, Gambi F, Sepede G, Valchera A, et al. (2009) Alexmia and its relationships with disassociative and Internet addiction in a non-clinical sample. Cyber Psychology and Behaviour 12: 67-69.

15. Robert JH, Barry JM, Richie P (2005) Association of Television viewing during childhood with poor educational achievement. J Biol Chem 159: 619-625. 